УДК 539.4

DOI 10.18101/2306-2363-2019-1-3-8

\title{
О ПРИРОДЕ ПАРАМЕТРА УРАВНЕНИЯ ЕНКЕЛЯ ДЛЯ ВЯЗКОСТИ СТЕКЛООБРАЗУЮЩИХ ЖИДКОСТЕЙ
}

\author{
(ㄷ Д. С. Сандитов \\ доктор физико-математических наук, профессор, \\ кафедра общей и теоретической физики, \\ Бурятский государственный университет \\ 670000, Улан-Удэ, ул. Смолина, 24a \\ E-mail: sanditov@bsu.ru
}

\section{(c) М. В. Дармаев}

кандидат технических наук, старший преподаватель, кафедра общей и теоретической физики, Бурятский государственный университет 670000, Улан-Удэ, ул. Смолина, 24а

E-mail: darmaev@bsu.ru

\section{(C) А. А. Машанов}

кандидат технических наук, доцент, кафедра общей и теоретической физики, Бурятский государственный университет 670000, Улан-Удэ, ул. Смолина, 24a

E-mail: Mashanov@bsu.ru.

Показано, что между эмпирической постоянной уравнения Енкеля D и температурой стеклования наблюдается линейная корреляция. Эта постоянная является однозначной функцией энергии делокализации атома. Из их интерпретации следует условие стеклования жидкости, основанное на выключении пускового механизма текучести. Последний сводится к процессу делокализации атома. На основе данных о температурной зависимости вязкости определены значения эмпирической постоянной уравнения Енкеля для ряда неорганических стекол и проверена линейность зависимости $D$ от температуры стеклования.

Ключевые слова: уравнение вязкости; текучесть; эмпирический параметр; делокализация атома; критерий стеклования; неорганические стекла; температура стеклования.

\section{Для цитирования:}

Сандитов Д. С., Дармаев М. В., Машанов А. А. О природе параметра уравнения Енкеля для вязкости стеклообразующих жидкостей // Вестник Бурятского государственного университета. Химия. Физика. 2019. Вып. 1. С. 3-8.

Отсутствие общепризнанной теоретической формулы для своеобразной температурной зависимости вязкого течения стеклообразующих жидкостей привело к появлению серии эмпирических соотношений [1]. Меерлендер [2] в результате сравнения наиболее распространенных пяти уравнений вязкости [Vogel-FulcherTamman (1921-1925), Waterton (1932), Jenkel (1939), Bradbury (1951), Cornelissen и др. (1957) [1]] с опытными данными приходит к заключению, что уравнение Енкеля (Jenckel) [3] 


$$
\eta=A \exp \left[\frac{B}{T}+\frac{C}{T} \exp \left(\frac{D}{T}\right)\right]
$$

наилучшим образом описывает вязкое течение стеклообразующих жидкостей в широком интервале температуры.

Настоящее сообщение посвящено обсуждению природы постоянной этого уравнения $D$ в рамках модели делокализованных атомов [4], что может дать определенную информацию о вязком течении и стекловании жидкостей.

Вывод уравнения Енкеля (1) с привлечением развиваемой модели позволяет связать эмпирический параметр $D$ с энергией делокализации атома $\Delta \varepsilon_{e}(\mathrm{k}-$ постоянная Больцмана) [5, 6]

$$
\Delta \varepsilon_{e}=k D
$$

Энергия $\Delta \varepsilon_{e}$ выражается через температуру стеклования $T_{g}$ и долю флуктуационного объема $f_{g}$, замороженную в области температуры $T=T_{g}$ [4],

$$
\Delta \varepsilon_{e}=k T_{g} \ln \left(1 / f_{g}\right)
$$

Величина $f_{g}$ определяется по данным о вязкости и слабо зависит от природы стеклообразных систем; у аморфных веществ одного класса она практически постоянна [4]

$$
f_{g}=\left(\frac{\Delta V_{e}}{V}\right)_{T=T_{g}} \approx \text { const }
$$

Флуктуационный объем $\Delta V_{e}$ обусловлен тепловыми смещениями (делокализацией) атомов: $\Delta V_{e}=N_{e} \Delta \mathrm{v}_{e}$, где $N_{e}$ - число делокализованных атомов, $\Delta \mathrm{v}_{e}-$ элементарный флуктуационный объем, необходимый для предельного смещения атома (объем делокализации атома).

Расчет $\Delta \varepsilon_{e}$ по формуле (2) из данных об эмпирической постоянной $D=2500 \mathrm{~K}[2]$ для силикатного стекла $(R-$ газовая постоянная)

$$
\Delta \varepsilon=R D=21 \kappa \text { цос } / \text { моль }
$$

находится в согласии с результатами расчета по уравнению модели (3) для щелочносиликатных стекол [4]

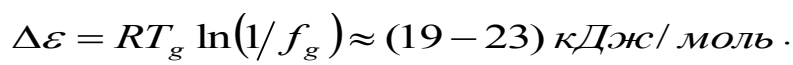

Из соотношений (2) и (3) при $f_{g} \approx$ const следует, что параметр $D$ должен быть пропорционален температуре стеклования $\left(D \sim T_{g}\right)$

$$
D=\left\lfloor\ln \left(1 / f_{g}\right)\right\rfloor T_{g} .
$$

На основе данных о температурной зависимости вязкости [7] мы определили значения $D$ для ряда неорганических стекол и проверили линейность зависимости $D$ от $T_{g}$. Как и следовало ожидать, у силикатных и германатных стекол пара- 
Д. С. Сандитов, М. В. Дармаев, А. А. Машанов. О природе параметра уравнения енкеля для вязкости стеклообразующих жидкостей

метр $D$ действительно линейно зависит от температуры стеклования $T_{g}$ (рис. 1 и 2). Однако прямые $D-T_{g}$ у этих стекол не проходят через начало координат. Развиваемое представление можно привести в соответствие с экспериментом, если в соотношение (5) введем эмпирическое слагаемое $D_{0}$ физический смысл которого остается не совсем ясным и требует в дальнейшем детального рассмотрения. Ниже ограничимся одним из возможных вариантов его интерпретации, согласно которому $D$ заметно больше $D_{0}$.

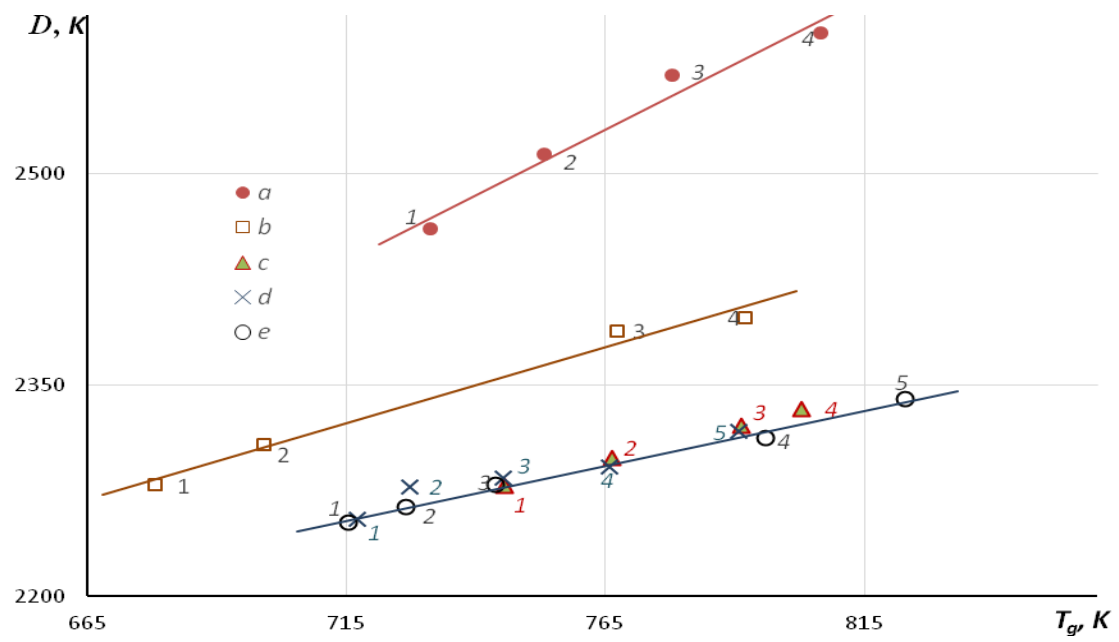

Рис. 1. Линейная корреляция между эмпирическим параметром уравнения Енкеля $D$ и температурой стеклования $T_{g}$ для двухкомпонентных силикатных и германатных стекол при различных содержаниях окислов.

$a-\mathrm{GeO}_{2}-\mathrm{Na}_{2} \mathrm{O}$ (содержание $\mathrm{Na}_{2} \mathrm{O}$, мол. \%: $\left.1-30,2-25,3-20,4-15\right) ; \quad b-\mathrm{SiO}_{2}-\mathrm{PbO}$ (РbO, мол. \%: $1-50,2-45,3-30,4-24,6)$; с - $\mathrm{SiO}_{2}-\mathrm{K}_{2} \mathrm{O}\left(\mathrm{K}_{2} \mathrm{O}\right.$, мол. \%: $1-25,2-20,3-15,4$ $-13) ; d-\mathrm{SiO}_{2}-\mathrm{Na}_{2} \mathrm{O}\left(\mathrm{Na}_{2} \mathrm{O}\right.$, мол. \%: $\left.1-33,2-30,3-25,4-20,5-15\right) ; e-\mathrm{SiO}_{2}-\mathrm{Li}_{2} \mathrm{O}\left(\mathrm{Li}_{2} \mathrm{O}\right.$, мол. \%: $1-33,3,2-30,3-25,4-14,5-10)$.

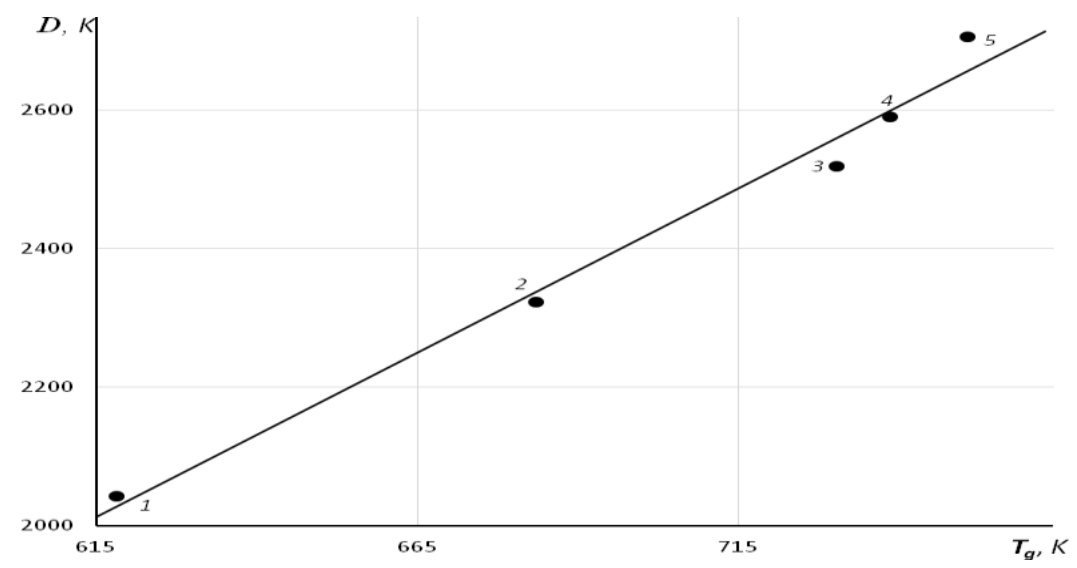

Рис. 2. Линейная корреляция между эмпирическим параметром уравнения Енкеля $D$ и температурой стеклования $T_{g}$ для двухкомпонентных натриево-боратных стекол при различных содержаниях окислов (содержание $\mathrm{Na}_{2} \mathrm{O}$, мол. \%: $1-10,2-15,3-20,4-25,5-30$ ). 


$$
D=\left\lfloor\ln \left(1 / f_{g}\right)\right\rfloor T_{g}+D_{0},
$$

Предположим, что делокализация атома - его предельное упругое смещение из равновесного положения - служит необходимым условием реализации элементарного акта вязкого течения. Без делокализации атома (пускового механизма текучести) невозможно вязкое течение. Поэтому замораживание процесса делокализации атома в области стеклования приводит к прекращению вязкого течения и к переходу расплава в стеклообразное состояние. Этот момент наступает тогда, когда энергия тепловых колебаний решетки, отнесенная к атому, становится равной или меньше энтальпии делокализации атома: $(i / 2) k T \leq \Delta H_{e}$, откуда следует условие перехода жидкость - стекло

$$
\Delta H_{e}=\frac{i}{2} k T_{g},
$$

где $i$ - число степеней свободы кинетической единицы, ответственной за стеклование, а энтальпия $\Delta H_{e}$ равна работе по предельному упругому смещению атома, совершаемой против внутреннего $p_{i}$ и внешнего $p$ давлений $\left(\Delta \varepsilon=p_{i} \Delta \mathrm{v}_{e}\right)$ [4]

$$
\Delta H_{e}=\left(p_{i}+p\right) \Delta \mathrm{v}_{e}=\Delta \varepsilon_{e}+p \Delta \mathrm{v}_{e}
$$

Критерий стеклования (7) с учетом (8) преобразуется в выражение

$$
\Delta \varepsilon_{e}=\frac{i}{2} k T_{g}-p \Delta \mathrm{v}_{e},
$$

откуда, принимая во внимание равенство (2), для параметра $D$ приходим к уравнению прямой

$$
D=\frac{i}{2} T_{g}-\frac{1}{k} p \Delta \mathrm{v}_{e}
$$

которое идентично соотношению (6), где $D_{0}$ получает следующую трактовку

$$
\left|D_{0}\right|=\frac{p \Delta \mathrm{v}_{e}}{k}
$$

Знак минус в равенстве (10) означает, что внешнее давление $p$ действует на поверхность системы снаружи во внутрь, а тепловое давление $p_{t}=(i / 2) k T_{g} / \Delta \mathrm{v}_{e}$ - наоборот, изнутри системы навстречу $p$. Равенство (10) [или (9)] представляет собой фактически уравнение состояния — баланс давлений [1]: $p_{i}+p=p_{t}$. При постоянном атмосферном давлении $p=$ const, параметр $D_{0}$, согласно (11), является однозначной функцией величины $\Delta \mathrm{v}_{e}$.

В силикатных стеклах «делокализация атома» представляет собой предельное смещение мостикового атома кислорода в мостике $\mathrm{Si}-\mathrm{O}-\mathrm{Si}$, связанное с локальной упругой деформацией кремнекислородной сетки из валентных связей $[4,5]$. Поэтому объем делокализации атома $\Delta \mathrm{v}_{e}$ у этих стекол определяется объемом мостикового атома кислорода. У стеклообразных систем одного класса $\Delta \mathrm{v}_{e} \approx$ const.

Обращает внимание то обстоятельство, что у трех щелочносиликатных стекол $\mathrm{SiO}_{2}-\mathrm{MeO}_{2}(\mathrm{Me}=\mathrm{K}, \mathrm{Na}, \mathrm{Li})$ экспериментальные точки на рис. 1 ложатся практически на одну прямую. Это означает, что параметры уравнения прямой (6) для 
Д. С. Сандитов, М. В. Дармаев, А. А. Машанов. О природе параметра уравнения енкеля для вязкости стеклообразующих жидкостей

них одинаковы, откуда следует, что $f_{g} \approx$ const и $D_{0} \approx$ const. В самом деле, значения $f_{g}$ и $\Delta \mathrm{v}_{e}$ У этих щелосносиликатных стекол примерно одинаковы [4]: $f_{g} \approx$ const $\approx 0.025-0.028$ и $\Delta \mathrm{v}_{e} \approx$ const $\approx(4-5) \AA^{3}$, откуда и $D_{0}$ является постоянной величиной.

Внутреннее давление жидкостей и твердых тел $p_{i}$, обусловленное силами межатомного (межмолекулярного) притяжения, существенно больше обычного атмосферного внешнего давления $p \approx 1$ атм [1]. При малых $p$ в сравнении с $p_{i}$ в равенстве (8) энтальпия $\Delta H_{e}$ приближается к энергии делокализации атома $\Delta \varepsilon_{e}$. Поэтому в данном случае вторые слагаемые в соотношении (9) и в равенствах (6) и (10) относительно малы.

Таким образом, эмпирическая постоянная $D$ в уравнении Енкеля (1) оказывается тесно связанной с температурой стеклования $T_{g}$. Обоснование указанного обстоятельства приводит к определенному критерию стеклования.

Работа выполнена при финансовой поддержке Министерства науки и высшего образования РФ (грант № 3.5406.2017/8.9).

\section{Литература}

1. Сандитов Д. С., Бартенев Г. М. Физические свойства неупорядоченных структур. - Новосибирск: Наука, 1982. - 259 с.

2. Meerlender G. Die erweiterte Jenckel-Gleichung, eine leistungsfähige Viskositäts temperature - formel. I, II // Rheol. acta. - 1967. - V. 6, № 4. - S. 309-377.

3. Jenckel E. Zur temperaturabhängigkeit der Viskosität Von Schmelzen // Z. Physik. Chem. - 1939. - Bd. 184, № 1. - S. 309-319.

4. Сандитов Д. С. Модель делокализованных атомов в физике стеклообразного состояния // ЖЭТФ. - 2012. - Т. 142, Вып. 1 (7). — С. 123-137.

5. Сандитов Д. С. Модель вязкого течения стеклообразующих жидкостей и стекол // ДАН. - 2013. - Т. 451, № 6. - С. 650-654.

6. Бадмаев С. С., Машанов А. А., Сандитов Д. С. Стеклование жидкости и спусковой механизм вязкого течения // Вестник Бурятского госуниверсита. Химия. Физика. 2018. - Вып. 4.- С. 54-58.

7. MDL ${ }^{\circledR}$ SciGlass - 7.8 Institute of Theoretical Chemistry, Shrewsbury, MA, 2012.www.sciglass.info.

\section{ON THE NATURE OF ENKEL EQUATION PARAMETER FOR VISCOSITY OF GLASS-FORMING LIQUIDS}

\section{S. Sanditov}

Doctor of Physics and Mathematics, Professor

Department of General and Theoretical Physics

Buryat State University, 670000, Ulan-Ude, Smolina, Str., 24a

E-mail: sanditov@bsu.ru

\section{V. Darmaev}

Candidate of Engineering

Department of General and Theoretical Physics

Buryat State University, 670000, Ulan-Ude, Smolina, Str., 24a

E-mail: darmaev@bsu.ru 
A. A. Mashanov

Candidate of Engineering

Department of General and Theoretical Physics

Buryat State University, 670000, Ulan-Ude, Smolina, Str., 24a

E-mail: Mashanov@bsu.ru

It is shown that there is a linear correlation between the empirical constant of Enkel equation $\mathrm{D}$ and glass transition temperature. This constant is an unambiguous function of the atom atom delocalization energy. Their interpretation follows the condition of the glass transition of the fluid based on the activation of a trigger of the flow. The latter leads down to the process of atom delocalization. On the basis of the data on temperature dependence of viscosity values of empirical constant of the Enkel equation for a number of inorganic glasses are defined and linearity of dependence of D on glass transition temperature is checked.

Keywords: equation of viscosity; fluidity; empirical setting; atom delocalization; criterion of glass transition; inorganic glasses; glass transition temperature. 